\title{
State-Wide Contracts for Library Materials: An Analysis of the Attendant Dysfunctional Consequences
}

\begin{abstract}
Traditional state-wide contracts for library materials awarded by the state to various vendors in behalf of state-supported college and university libraries regularly incur dysfunctional consequences that far outstrip their intended benefits. More than negating the proposed value of such contracts, these undesirable consequences result in excessive expenditure of library staff time that greatly exceeds projected savings predicated upon discounts to be gained through traditional procedures.
\end{abstract}

S STATE-WIDE CONTRACTS FOR LIBRARY READING MATERIALS are perennially a topic of interest in the quest for greater economy in state-supported academic library acquisition programs. The impetus for considering such contracts has come both from within and without libraries. ${ }^{1}$ However, there is a dearth of literature on the topic for librarians, purchasing agents, and other interested individuals who wish to peruse arguments for and against such provisions. Though side-wide contracts often have sparked controversy and have prompted recent investigations in several states, little information has reached the open literature. $^{2}$

This article summarizes the principal conclusions drawn from an appraisal of the appropriateness of state-wide contracts for academic libraries. To provide a broadly-based review, representatives of the three aforementioned pri-

Calvin J. Boyer is an assistant professor, Graduate Library School, Indiana University. The author wishes to acknowledge the assistance of Ms. Louise Gregg. mary interest groups-the state, the library, and the supplier of library materials-were contacted to secure facts and opinions.

Directors of forty-five state purchasing agencies were contacted by letter to determine if their respective states required state-supported libraries to purchase library materials from a vendor holding a state-wide contract, what characteristics (if any) of library materials as a commodity set them apart from other commodities for which the state negotiated state-wide contracts, and what undesirable consequences (if any) did such contracts force upon libraries and the state.

Library directors or technical service directors of fifty state-supported college and university libraries were also contacted by letter. The sample was purposefully structured to provide a wide array of libraries (size of budget, age of library, parent institution, etc.) including both libraries which operate under state-wide contracts and those free to negotiate their own contracts. The inquiry sought to identify the two pri- 
mary dysfunctional consequences of such contracts as viewed by each individual respondent.

Executive officers of ten library wholesalers were queried to determine similar data and to ascertain whether the wholesaler would welcome an extension in the number of states awarding statewide contracts. In each of the three categories telephone conversations were used to supplement or clarify issues raised.

The resulting mosaic of information represents insights offered by state purchasing agents, administrative representatives of major library wholesalers, and librarians employed in libraries, some of which were covered and some not, by such contracts.

State-wide contracts for various commodities have traditionally been advocated as a means of control and/or economy. Historically, the role of the state in controlling purchasing activities of subordinate units (divisional, departmental, or institutional) was created to comply with purchasing statutes enacted by state legislatures.

Through combinations of various circumstances, original intent, experience, etc., all states have added provisions to modify certain traditional centralized purchasing procedures which were deemed detrimental to the best interest of the state. One of the most common modifications of centralized procedures is the delegation of authority over control of purchasing procedures to the unit directly involved. Another modification is the exemption of a commodity from existing controls. Presently library materials for academic libraries are one of the most widely exempted commodities from such state-wide controls. ${ }^{3}$

Apart from economic considerations, benefits derived by the state through use of contracts as a means of control are difficult, if not impossible, to assess. Information supplied by purchasing agents, librarians, and wholesalers of li- brary materials fails to substantiate the contention of contract advocates who claim that the state is better served by direct control (typified by state-wide contracts), than it would be if such control were vested in individual institutions.

In contrast, use of such contracts as a means of economy are not so difficult to assess. Unmistakable evidence demonstrates that state-wide contracts are a disservice to the principal parties involved-the state, the library, and the vendor. Frank Rogers, director of the library at Portland State University, Oregon, firmly denounces the theory underlying the contract system:

It is presumably intended to provide open competition for the privilege of supplying library materials for a stated period of time at the lowest possible cost. But its effect is to prevent the librarian, for that period of time, from competing for the best bargains of a combination of price and service. ${ }^{4}$

Moreover, fact and opinion together indicate that in the best of circumstances such contracts have returned negligible savings; in less favorable circumstances, compliance with contract provisions has caused both libraries and the state to expend unnecessary sums (time and money) greater than those ever likely to be recovered by utilization of such contracts. Typically, libraries bound by such contracts are forced to spend precious staff time and portions of limited budgets when faced with a change of contractors and/or inadequate service from the vendor. In recent instances, further hardships have been noted when a contractor failed to execute a contract by withdrawing midway through the contract period.

Advocates of contracts as a means of economy emphasize discounts gained through competitive bidding. Yet discounts are at best only a partial indication of the economic success or failure of a contract. A wholly superior way to 
measure economy achieved through contracts is to consider actual total expenditure (time and money) determined from cost of each piece acquired, including necessary expenditures to acquire materials which the contract vendor could not, or would not, supply. Henry Knouft, director of purchases, State of Kansas, reported that experience with competitive bidding led to Kansas' adoption of its present policy of institutional autonomy:

The realization that any saving achieved through competitive bidding was quickly overcome by slow, incomplete deliveries, build-up of backordered items, and uncertain availability of items resulted in our present policy (institutional autonomy). ${ }^{5}$

A hypothetical example plus sound thoughts by authorities in the business will clarify important issues quickly and simply. Vendors A and B bid discounts of 30 percent and 35 percent respectively.

Knowledgeable bookmen (librarians and book sellers alike) will recognize that there can be two legitimate approaches to the service of library acquisitions. On the one hand, a company can go for discount, supplying what it stocks, or what it can secure easily, with a highly rated discount. Indeed, this approach has validity in many library purchasing situations (most of which are foreign to academic library programs, i.e., such an approach is more suited to meeting the needs of school and public libraries). It is necessary, however, in this context to limit service to those several hundred publishers who discount very favorably to the book trade, and, more importantly, who publish frequently. The business ideal here is to turn over many, many individual titles to many libraries, thus capitalizing on mass production.

The other approach allows a company to capitalize on the value of dealing with nearly all publishers, regardless of discount or frequency of publica- tion. This approach emphasizes the uniqueness of the research library's needs, that is, the ordering of virtually unique (to itself) books that will fit its specific informational needs. The book dealer here releases library technical processing staff from time-consuming task of verifying many separate entries, and the need to proliferate hundreds, perhaps thousands, of separate orders to individual publishers. This service from a dealer may be translated into smaller discounts, but it implies that individual items will be obtained, regardless of difficulty in securing (the items). 6

On the basis of discounts offered, Vendor B appears to be the preferred vendor. In actual practice, however, Vendor B returns twice as many unfulfilled requests for materials as does Vendor $A$, indicating that he cannot supply such materials. (It is commonly acknowledged that no vendor is prepared to provide all materials.) When a systematic assessment of economy provided by Vendors A and B is completed, Vendor A becomes the preferred vendor. As one astute observer (Daniel Melcher in Melcher on Acquisition) suggests: "Discounts offered should never be interpreted to apply to all the materials you want; rather, the interpretation should include only those materials which you want which the vendor can and will supply." M. A. Kinley, chief, Purchasing and Supply Division, State of Hawaii also cautions: “. . . some dealers tend to supply only what is convenient and profitable to them in spite of contract intent, and it is extremely difficult to prove that the supplier deliberately failed to perform."

In some cases, the high discount dealer blatantly refuses to handle certain types of materials needful to college and university libraries. Many purchases of academic libraries consist of materials published by associations and nonprofit organizations. These materials carry no discount to dealer or library, 
can be ordered directly from the source, but entail tremendous paper work in handling individual small orders and payments. A good dealer, though of necessity offering a low discount schedule, will obtain a large proportion of these nonprofit materials for a library, thereby saving the library considerable time and trouble, whereas the high discount dealer makes no pretense of handling these types of materials-he simply refuses outright. ${ }^{9}$

Too often, due to difficulty of measuring levels of service, undue emphasis is placed upon discounts. Nevertheless, in spite of this continued emphasis upon discount in many quarters, some library agencies have negotiated contracts on an entirely different basis. One alternative is the master contract. As defined in Publishers' Weekly:

... the master contract defines a new way of paying book jobbers. Instead of trying to set up a complicated series of discounts from list price depending upon whether a book is a trade book, a textbook, a foreign-published book or a book from an academic press, this contract states that the buyer shall pay the vendor's cost for the book, plus a flat fee which is designed to pay for jobber's services and give him a reasonable profit. ${ }^{10}$ (emphasis added)

The most cogent argument of contract advocates for economic justification of such contracts appears to be partially, if not wholly, unsubstantiated if one carefully examines the variables involved by the vendor in determining discounts offered. Those who contend that better discounts are secured by emphasizing the collective purchasing power of libraries of state-supported academic institutions erroneously emphasize the importance of the amount involved in the contract as a primary variable.

Robert Jones, vice-president, Josten's has successfully summarized the dilemma of jobbers:
A combine of libraries ordering one each of 20,000 titles per year to be shipped and billed to ten locations is no more valuable an account, in terms of profit to the jobber, than a single library ordering one each of 2,000 titles per year. The only savings accrual to the jobber which can reasonably be expected to be passed on to the library occurs when a central agency combines orders for the same title from various branches and then orders in quantities for shipment to one location and pays promptly.

For all colleges in one state to bind together for the purpose of awarding all their book business to one jobber without combining their orders or having shipments and billings made to one place is simply a display of clout. Although there is no saving to the jobber, he will undoubtedly offer a larger discount on a statewide contract out of fear of losing some customers and/ or a competitor getting them.

That may sound insane, but unfortunately it is true, as witness the demise of a number of jobbers, paradoxically, during a period of unprecedented growth in the library field. McClurg's is gone. Campbell and Hall is in semireceivership. Bro-Dart lost money in 1971 and made a tiny profit in 1972. H. R. Huntting Company is just not doing well, Xerox is getting out of the business, and about a half dozen other smaller jobbers have just gone out of business. ${ }^{11}$

What is misleading to many observers is that the contract amount is not a principal variable-rather, it is a secondary one! The uniqueness of the book and other library materials as commodities and the purchasing patterns of academic libraries largely relegate the dollar volume of the contract to a place of secondary importance. Primary variables used by wholesalers of library materials to determine discount rates are:

1. The mix of orders for stock vs. nonstock items.

2. The average price of materials ordered. 
3. The prevalence of orders for multiple copies.

4. The reporting and invoicing requirements set by the contract.

5. Payment rapidity. ${ }^{12}$

Even the casual observer will note that such contracts do not materially improve the competitive advantage of the state in that the acquisition patterns of materials ordered by individual libraries bound by such contracts remain unchanged.

A portion of fault lies with the state in this respect. Under contract provisions, the state approaches prospective vendors as if the libraries involved were a single entity with which the vendor must interact. In most states, the great gamut of libraries of state-supported institutions indicates that a single, even cursory examination will readily yield an understanding of dissimilar needs for materials and services among institutions. The point is underlined by contrasting the library system of the multiversity requiring the services of several hundred vendors to meet the needs of a voracious acquisitions program with the library of a college or small university judiciously selecting only a fraction of available materials, most of which are easily obtainable from reputable vendors.

If contract discounts offered by a wholesaler do not differ appreciably between a contract negotiated by an individual and a collective one negotiated by the state, is there reasonable cause for rejecting state-wide contracts as a viable alternative? Overwhelming evidence demonstrates that concomitant dysfunctional economic consequences far outweigh any demonstrated benefits.

The inferior status of the traditional state-wide contract is most clearly seen in four situations:

1. A change of contractors.

2. Inferior service offered by contract vendor.

3. A vendor dropping the contract midway through the contract period.

4. Limited variety and/or varied quality of services offered by vendors.

While these difficulties may be experienced by libraries operating under individually negotiated contracts, the difficulties need not be simultaneously experienced by all within the respective state as is the case of libraries bound by state-wide contracts.

A brief review of the unique qualities of library materials as commodities will promote an understanding of the causes and consequences of such diffculties. Each title, whether of a book, journal, film, or recording is a unique entity. Titles are not interchangeable in spite of similar topic coverage. Each item is originally available from a single source, the publisher. Unlike myriad other commodities purchased by the state, library materials cannot be periodically purchased in quantity lots (exceptions are block purchasing of secondhand collections, opening-day collections, etc.) to be stockpiled for subsequent need. Rather, library materials must be processed title by title. Foreign to the acquisition routines of libraries are such common purchasing concepts as ream, gross, carload lot, hundredweight, assortment, etc.

The item-by-item acquisitions process has special import when considering the economic issues of contracts. Traditionally, libraries have been built title by title. Any attention to orders outstanding or canceled must be an item-by-item process. Replacement of unfilled contract orders with a second vendor potentially doubles the cost of acquiring the title.

The most critical situation in which libraries under a contract find themselves is one in which the vendor reneges on his pledge to complete the contract. Although not a common occurrence, the 
devastating effects of a single occurrence offset by manyfold past and future savings (if, indeed, there are such) which advocates propose such contracts achieve through improved discounts.

Like individual institutions, states, in awarding contracts, may err in spite of careful inquiry into past performance and present fiscal condition of the vendor. State-wide contracts insure that all institutions are involved-a situation most unlikely under local autonomy if one observes vendor-preference patterns of libraries throughout the country.

A prime example of the disastrous effects of a vendor dropping a contract midway through the award period occurred recently in Texas. A vendor holding the state-wide contract for journals was unable to fulfill the contract. The expenditure of time and money needed to overcome the confusion of thousands of unclear journal records in a title-bytitle process involving more than twenty university libraries, all of them attempting to cope with duplicate journal subscriptions, lapsed journal subscriptions, missing issues, and permanently incomplete volumes, though calculable, is staggering. Incalculable and irreparable is the extent of damage to services that normally would have been extended to library patrons during this period.

As observed earlier, the diverse needs of libraries-the multiversity library system vs. the college library-create a situation in which acceptable service to one library may be totally unacceptable to another. A 20 percent unfilled orderrequest rate to a library ordering 2,000 times per year may be acceptable. The identical rate to a library ordering 50,000 items per year may not be acceptable. Under state-wide contracts, seldom if ever will all libraries be equally served. Yet, such contracts preclude those libraries incurring inadequate service from contracting with a different vendor. In this circumstance, to continue the contract is a disservice to some; to terminate the contract is a disservice to others. As Robert Jones of Josten's observed: "The point is that service must have a value and the person best able to judge is the person receiving the service. Also, the value of service is in the eyes of the beholder. What is good service to one may be abominable to another." 13

It is nearly inevitable under such contracts that all libraries within a state must frequently labor unnecessarily under less than satisfactory vendor performance because of hesitancy on the part of the state to cancel the contract. Too many such contracts have been allowed to lapse at the end of the contract period rather than terminated to alleviate the adverse situation in which libraries found themselves. Too few contracts have been canceled in spite of just cause, as is amply demonstrated by libraries.

Unfortunately, as many states have concluded, changing contractors too often merely shifts dissatisfaction from one vendor to another. The change does not attack the cause of dissatisfaction, i.e., the inability of a single vendor to provide equally acceptable levels of service to a heterogeneous group of libraries bound by a state-wide contract.

Changing contractors adds an increased burden universally to state-supported academic libraries. Once the contractor becomes aware of the loss of the contract, the incentive to fill outstanding orders becomes solely one of economic considerations. Special attention is reserved for those libraries which will be continuing customers. The reordering of needlessly canceled less profitable items which might have been fulfilled if the contract were to be renewed is a burden placed upon libraries as one more dysfunctional consequence of such contracts.

Astute librarians have been quick to assimilate bibliographic services offered by various, but not all, vendors. Such 
services have been used to supplement acquisition routines of the library as a means of significantly stretching limited budgets. Fortunately for libraries, the array of services is ever-increasing. Primary examples are: standing orders, approval plans, preprocessed materials, and machine-readable bibliographic data.

Libraries which have integrated these services into their acquisition routines must exercise great care to insure that they continue without interruption. Libraries which have concentrated or shifted a major portion of the technical services processing functions to vendors (a prime example is the newly established academic library) are particularly vulnerable to the undesirable, often disastrous, consequences of statewide contracts.

Ample evidence gained through experience illustrates that the quality of services offered by vendors varies significantly in character and quality. Such variations preclude the use of some vendors by a library dependent upon a particular service. In this instance, the diverse needs of academic libraries coupled with the diverse capabilities of vendors highlights yet another limitation of state-wide contracts.

The proposition that the needs of academic libraries differ significantly is probably best illustrated by the actions of those states which exclude such libraries from the provisions of centralized purchasing altogether-the present position of a great majority of the states-and to a lesser extent by those states which:

1. offer libraries access to multiple contractors, e.g., New York. (Unless the state insures that acceptable services are available to all libraries bound by contract provisions, multiple contracts may be little better than the single contract.)

2. permit libraries discretionary use of existing contracts, e.g., Connecticut.

3. exempt certain libraries from contract provisions, often major university libraries, e.g., Minnesota.

No summary of principal conclusions would be complete without some consideration of the effects of state contracts upon vendors. Such contracts in effect lock out those vendors whose philosophy of service emphasizes extensive bibliographic services, including speed of delivery; willingness to obtain publications from minor publishers (associations and other nonprofit publishers) which offer little or no discount; accepting local requirements for invoicing and reporting, etc. Some vendors which enjoy a national reputation for excellent services simply never bid on such contracts, an action clearly indicating the direct relationship between service and discount. Other vendors periodically offer bids that are rejected primarily because service is difficult to measure. While discount rates are simple to comprehend as isolated entities, they may be deceptive to the observer not familiar with the unique characteristics of library materials and their supply systems.

Few will debate the proposition that the extent and quality of services offered by the contract vendor upon which academic libraries are becoming increasingly dependent as a means of greater economy are directly related to discounts offered. As discussed previously, state-wide contracts force vendors to accept portions of contracts which they neither want nor can handle adequately. Too, such contracts may defeat the very purpose for which they were intendedto provide competition among jobbers to insure the best possible price to the state-as mentioned earlier by Jones and in the following observation by a librarian:

It seems to me that a very unhealthy business situation is created. I will illustrate by my own experience. When- 
ever the time approaches to publish the new invitation to bid, the Texas state college librarians look for ways to retain the present state contractor. We have already experienced at least two contract breakdowns, and want no more. Therefore, we are aiding in the creation of a monopolistic contractor. . . . Presumably, the law was intended to obtain the best price for the participating library. As the monopoly grows, the participating library will obtain a progressively less favorable price. ${ }^{14}$

\section{SUMMARY}

Amassed throughout the inquiry was evidence that few, if any, advantages accrue to the state, the library, or the vendor through utilization of state-wide contracts. Though theoretically negligible savings are possible through the utilization of such contracts, actual practice indicates that concomitant dysfunctional consequences of state-wide contracts result in needless expenditures annually which outstrip manifoldly any suggested savings achieved through discounts derived from competitive bidding.
As observed by purchasing agents, librarians, and library vendors, the library may enjoy equal benefits through individually-negotiated contracts and integration of other sound business practices into acquisition procedures as the state can gain by the collective contract. Moreover, the library under the individually negotiated contract is not subject to the diverse and destructive dysfunctional consequences inherent in state-wide contracts.

These conclusions are not unique to this investigation. The states of California and Oregon, after extensive formal inquiry into the potential applicability of such contract provisions, rejected such provisions as detrimental to the interests of both the state and its libraries. ${ }^{15}$ Informal inquiries in other states conducted by librarians have rejected state contracts citing the same dysfunctional consequences. ${ }^{16}$ In summation, the state and its state-supported academic libraries can be better served by allowing each individual library to select the optimum method of meeting its own unique set of needs.

\section{REFERENCES}

1. Throughout the remainder of this paper, the use of the term "contract" or a variant form connotes state-wide contracts for library reading materials negotiated by the state in behalf of all state-supported academic libraries within the state. While many of the observations in this paper may be applicable to circumstances in which state contracts cover only a portion of statesupported academic libraries or other circumstances in which libraries retain the option of whether or not to utilize existing state-wide contracts, the focus of the investigation was upon circumstances in which all academic libraries of state-supported institutions are bound by contracts negotiated by the state.

2. One of the most perceptive accounts of the interactions between libraries and library suppliers is: Daniel Melcher with Margaret Saul, Melcher on Acquisition (Chicago:
American Library Association, 1971). While Melcher's focus is larger than the focus of this paper, many of the insights offered are wholly applicable. The title ought to be perused thoroughly by anyone interested in the topic of contracts.

3. More than three-quarters of the states surveyed exempt library materials from such contract provisions.

4. Personal letter written by Frank Rogers, director of the library, Portland State University, Oregon, to the author on 13 Nov. 1972.

5. Personal letter written by Henry $H$. Knouft, director of purchases, State of Kansas, to the author on 30 Oct. 1972.

6. Observation by Don Chvatal, representative Richard Abel and Co., Inc.

7. Melcher, Melcher on Acquisition.

8. Personal letter written by M. A. Kinley, chief, Purchasing and Supply Division, 
State of Hawaii, to the author on 14 Nov. 1972.

9. Library, Sacramento State College, California. "Some Comments on the Matter of Centralized Purchasing of Library Books," 1965.

10. Publishers' Weekly, 196:23 (1 Dec. 1969).

11. Personal letter written by Robert A. Jones, vice-president, Library Services, Josten's to the author on 28 Nov. 1972.

12. Telephone conversation between Arthur Brody, president, Bro-Dart Company, and the author, 8 Nov. 1972.

13. Personal letter written by Robert A. Jones, op. cit.
14. Personal letter written by Louis Maloney, librarian, Southwest Texas State University, Texas, to the author on 6 Dec. 1972.

15. Personal letter written by John S. Babich, chief of procurement, Department of General Services, State of California, to the author on 3 Nov. 1972; Educational Coordinating Council, Oregon. Joint Library Committee Report, 1972.

16. Personal letter written by Dewey E. Carroll, director of libraries, The University of Tennessee at Chattanooga, Tennessee, to the author on 2 Nov. 1972; personal letter written by Dan W. Graves, director of libraries, Clarion State College, Pennsylvania, to the author on 3 Nov. 1972. 